\title{
Correction to: Investigating market power in the Belgian pork production chain
}

\section{Dries Maes $^{1,2} \cdot$ Mark Vancauteren $^{1,3} \cdot$ Steven Van Passel ${ }^{1,4}$}

Published online: 12 December 2019

(C) The Author(s) 2019

\section{Correction to: Review of Agricultural, Food and Environmental Studies https://doi.org/10.1007/s41130-019-00096-6}

The article "Investigating market power in the Belgian pork production chain", written by Dries Maes, Mark Vancauteren and Steven Van Passel, was originally published electronically on the publisher's internet portal (currently SpringerLink) on 27 November 2019 without open access. The original article was corrected.

With the Society's decision to grant Open Access the copyright of the article changed in December 2019 to (C) The Author(s) 2019 and the article is forthwith distributed under the terms of the Creative Commons Attribution 4.0 International License (http://creativecommons.org/licenses/by/4.0/), which permits use, duplication, adaptation, distribution and reproduction in any medium or format, as long as you give appropriate credit to the original author(s) and the source, provide a link to the Creative Commons license, and indicate if changes were made.

Publisher's note Springer Nature remains neutral with regard to jurisdictional claims in published maps and institutional affiliations.

The online version of the original article can be found at https://doi.org/10.1007/s41130-019-00096-6

Dries Maes

dries.maes@vlaanderen.be

1 Faculty of Business Economics, Hasselt University, Diepenbeek, Belgium

2 Departement of Economy, Science and Innovation, Flemish Government, Brussels, Belgium

3 Statistics Netherlands, Heerlen, The Netherlands

4 Faculty of Business and Economics, University of Antwerp, Antwerp, Belgium 